\title{
The EGFR Family: Not So Prototypical Receptor Tyrosine Kinases
}

\author{
Mark A. Lemmon ${ }^{1}$, Joseph Schlessinger ${ }^{2}$, and Kathryn M. Ferguson ${ }^{3}$ \\ ${ }^{1}$ Department of Biochemistry and Biophysics, University of Pennsylvania Perelman School of Medicine, \\ Philadelphia, Pennsylvania 19104 \\ ${ }^{2}$ Department of Pharmacology, Yale University School of Medicine, New Haven, Connecticut 06520 \\ ${ }^{3}$ Department of Physiology, University of Pennsylvania Perelman School of Medicine, Philadelphia, \\ Pennsylvania 19104 \\ Correspondence: mlemmon@mail.med.upenn.edu
}

The epidermal growth factor receptor (EGFR) was among the first receptor tyrosine kinases (RTKs) for which ligand binding was studied and for which the importance of ligand-induced dimerization was established. As a result, EGFR and its relatives have frequently been termed "prototypical" RTKs. Many years of mechanistic studies, however, have revealed that-far from being prototypical-the EGFR family is quite unique. As we discuss in this review, the EGFR family uses a distinctive "receptor-mediated" dimerization mechanism, with ligand binding inducing a dramatic conformational change that exposes a dimerization arm. Intracellular kinase domain regulation in this family is also unique, being driven by allosteric changes induced by asymmetric dimer formation rather than the more typical activationloop phosphorylation. EGFR family members also distinguish themselves from other RTKs in having an intracellular juxtamembrane (JM) domain that activates (rather than autoinhibits) the receptor and a very large carboxy-terminal tail that contains autophosphorylation sites and serves an autoregulatory function. We discuss recent advances in mechanistic aspects of all of these components of EGFR family members, attempting to integrate them into a view of how RTKs in this important class are regulated the cell surface.

$\mathrm{T}_{\mathrm{i}, \mathrm{s}}$ he epidermal growth factor receptor (EGFR) is often considered the "prototypical" receptor tyrosine kinase (RTK) and has been intensively studied. It is one of a family of four RTKs in humans, the others being ErbB2/ HER2, ErbB3/HER3, and ErbB4/HER4 (Fig. $1)$. EGFR and its relatives are known oncogenic drivers in cancers such as lung cancer (Mok 2011), breast cancer (Arteaga et al. 2011), and glioblastoma (Libermann et al. 1985; Lee et al. 2006a; Vivanco et al. 2012), and inhibitors of these receptors have been among the most successful examples of targeted cancer therapies to date (Arteaga 2003; Moasser 2007; Zhang et al. 2007), including antibody therapeutics (e.g., trastuzumab and cetuximab) and small-molecule tyrosine kinase inhibitors (e.g., erlotinib, gefitinib, lapatinib).

Far from being prototypical, however, it is now clear that regulation of EGFR family mem-

Editors: Joseph Schlessinger and Mark A. Lemmon

Additional Perspectives on Signaling by Receptor Tyrosine Kinases available at www.cshperspectives.org

Copyright (C) 2014 Cold Spring Harbor Laboratory Press; all rights reserved; doi: 10.1101/cshperspect.a020768

Cite this article as Cold Spring Harb Perspect Biol 2014;6:a020768 
M.A. Lemmon et al.
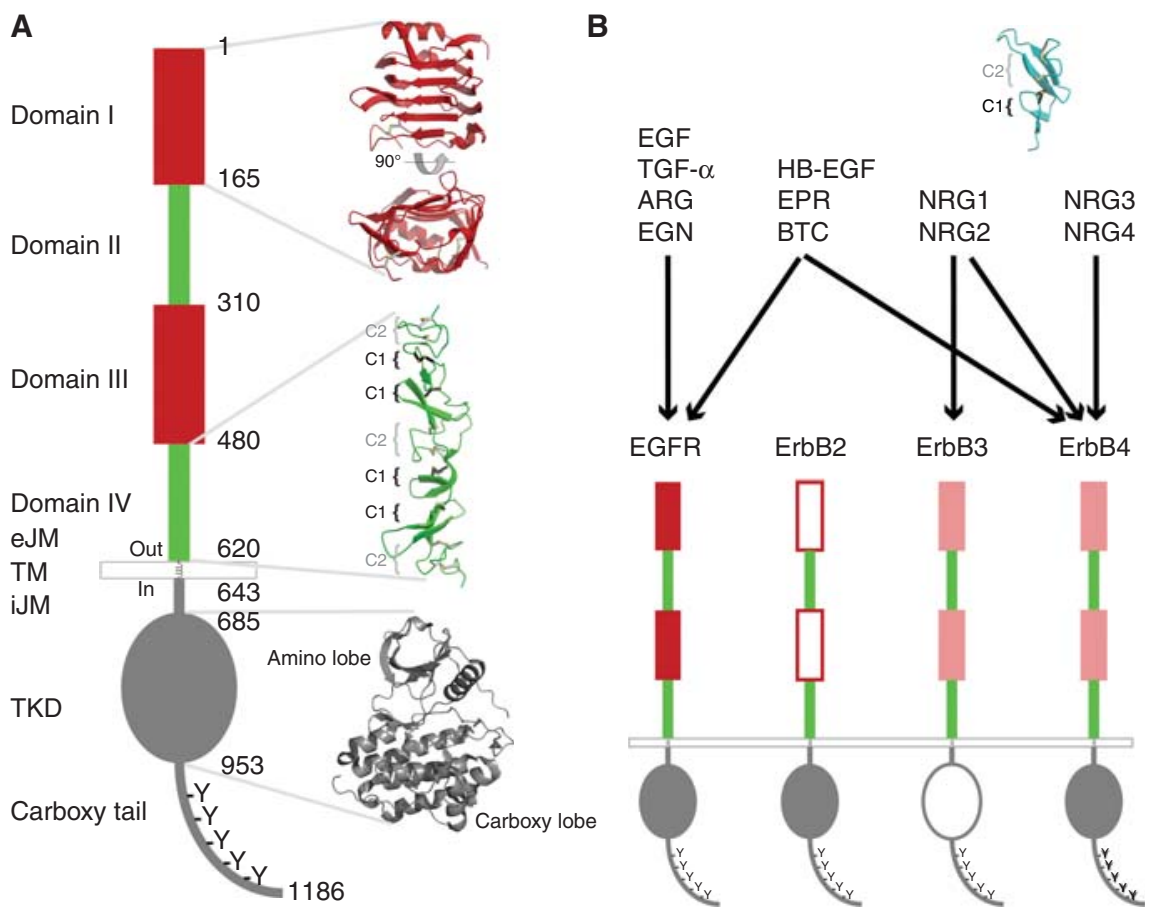

Figure 1. Schematic representation of EGFR/ErbB family receptors and their ligands. $(A)$ The domain composition of human EGFR is shown. The extracellular region contains four domains: Domain I (amino acids 1165), domain II (amino acids 165-310), domain III (amino acids 310-480), and domain IV (amino acids 480620). Domains I and III are closely related in sequence, as are domains II and IV. Shown are representations of the structures of domains I and IV. Domain IV contains two types of disulfide-bonded module (C1 and C2). In C1 domains, a single disulfide constrains an intervening bow-like loop. In C2 modules, two disulfides link four successive cysteines in the patterns $\mathrm{C} 1-\mathrm{C} 3$ and $\mathrm{C} 2-\mathrm{C} 4$ to give a knot-like structure. A short extracellular juxtamembrane (eJM) region separates the extracellular region from the $\sim 23$-amino-acid transmembrane (TM) domain. Within the cell, a short intracellular juxtamembrane (iJM) region separates the tyrosine kinase domain (TKD) from the membrane. A representative EGFR TKD structure is shown. The TKD is followed by a carboxy-terminal largely unstructured tail (amino acids 953-1186) that contains at least five tyrosine autophosphorylation sites. $(B)$ EGFR is one of four members of the EGFR/ErbB family in humans. The other members are ErbB2/HER2, for which no soluble activating ligand is shown; ErbB3/HER3, which has a significantly impaired kinase domain (Jura et al. 2009b; Shi et al. 2010); and ErbB4/HER4. The primary active moiety of the ligands for these receptors is the EGF-like domain, shown as a cartoon structure (top right). EGFR is activated by the EGFR agonists: EGF itself, TGF- $\alpha$ (transforming growth factor $\alpha$ ), ARG (amphiregulin), and EGN (epigen). The bispecific ligands regulate both EGFR and ErbB4: HB-EGF (heparin-binding EGF-like growth factor), EPR (epiregulin), and BTC (betacellulin). Neuregulins (NRGs) 1 and 2 regulate ErbB3 and ErbB4, whereas NRG3 and NRG4 appear to be specific for ErbB4 (Wilson et al. 2009).

bers is unique among RTKs (Ferguson 2008; Lemmon 2009; Lemmon and Schlessinger 2010). Structural studies have revealed how the $\sim 620$-amino-acid isolated extracellular region is induced to dimerize after growth factor binding (Burgess et al. 2003) and how the isolated intracellular tyrosine kinase domain (TKD) becomes allosterically activated after forming an asymmetric dimer (Zhang et al. 2006; Jura et al. 2009a; Red Brewer et al. 2009). These findings have typically been interpreted in the context of a model in which EGF family receptors are regulated through ligand-induced receptor homodimerization or heterodimerization, with growth factor binding converting the receptor from an inactive monomeric configuration to 
an active dimeric conformation (Yarden and Schlessinger 1987; Schlessinger 1988, 2014; Ullrich and Schlessinger 1990). Although this original model has stood the test of time and initiated a whole field of studies of ligand-induced RTK dimerization, recent work has provided highly sophisticated views of a unique mode of allosteric regulation used by EGFR.

\section{ErbB RECEPTORS AND THEIR LIGANDS}

Although EGFR/ErbB family members are most frequently considered in the context of human cancer-where EGFR, ErbB2, and ErbB3 are validated therapeutic targets-the biology of these broadly expressed receptors is very complicated (Yarden and Sliwkowski 2001; Burgess 2008). The effect of knocking out the EGFR gene in mice ranges from embryonic lethality in one genetic background to death at birth in another, to postnatal death in yet another (Sibilia et al. 2007). Defects are seen in bone, brain, heart, and various epithelia-notably skin, hair, eyes, and lungs. Mouse knockouts of ErbB2, ErbB3, or ErbB4 are all embryonic lethal, also with neurodevelopmental and cardiac defects in each case (Sibilia et al. 2007; Burgess 2008). It is now clear that ErbB 2/3/4 signaling has a key role in both cardiac development and maintenance of cardiac function in the adult (Pentassuglia and Sawyer 2009).

EGFR is regulated by at least seven different activating ligands in humans (Harris et al. 2003; Schneider and Wolf 2009) listed in Figure 1: EGF itself, transforming growth factor $\alpha$ (TGF- $\alpha$ ), betacellulin (BTC), heparin-binding EGF-like growth factor (HB-EGF), amphiregulin (ARG), epiregulin (EPR), and epigen (EGN). Each contains an EGF-like domain that is responsible for receptor binding and activation, with a characteristic pattern of six spatially conserved cysteines (that form three intramolecular disulfides). The EGFR ligands are all produced as membrane-bound precursor proteins (Harris et al. 2003) and are cleaved by cell-surface proteases to yield the active growth factor species as described by Adrain and Freeman (2014). Although defects in EGFR affect a wide range of processes, it remains unclear which ligands are responsible in which context-with a few exceptions (Fiske et al. 2009). ErbB3 and ErbB4 are regulated by neuregulins (NRGs) (Falls 2003) — also called heregulins (HRGs), a family of ligands produced from four genes (NRG1$N R G 4$ ) in a wide variety of different isoforms that all contain an EGF-like domain. NRG1 and NRG2 bind both ErbB3 and ErbB4, whereas NRG3 and NRG4 appear to be ErbB4 specific (Wilson et al. 2009). The NRGs and their receptors have an important role in nervous system development (Birchmeier 2009). NRG1 and ErbB4 have been linked to schizophrenia (Rico and Marín 2011). Three of the EGFR ligands mentioned above (BTC, EPR, and HB-EGF) also bind and activate ErbB4 and are termed "bispecific" ligands (Riese and Stern 1998; Wilson et al. 2009). For ErbB2, no soluble ligand has been identified despite a great deal of investigation in the 1990s. This orphan receptor is generally assumed only to be regulated by heterodimerization with other ErbB family receptors, although its close structural resemblance to the Drosophila melanogaster EGFR suggests that membrane-associated ErbB2 ligands may remain to be discovered (Alvarado et al. 2009).

Each ErbB ligand is produced as a membrane-bound precursor that is processed in a ligand-specific manner (Buonanno and Fischbach 2001). Although the EGF-like domains of the NRGs and the EGFR ligands appear to be sufficient for much of their biological effect, it is clear that other parts of the full-length ligands do influence signaling - although in ways that are not yet fully understood. The discussion in this review is limited to receptor activation by the EGF-like domains. The receptors themselves (Fig. 1) all have a large extracellular region of $\sim 620$ amino acids that can be subdivided into four domains. Domains I and III are related to one another (and to similar domains in the insulin receptor) and serve as the primary ligandbinding regions. Domains II and IV are cysteine-rich domains that share similarities with laminin repeats (Ward et al. 1995) and contain a string of disulfide-bonded modules. A single transmembrane domain links the extracellular region to the $\sim 540$-amino-acid intracellular region of the receptor that contains a tyrosine 
M.A. Lemmon et al.

kinase domain as well as a carboxy-terminal "tail" of $\sim 230$ amino acids. Binding of activating ligands to EGFR or ErbB4 promotes strong homodimerization of these receptors (Ferguson et al. 2000). In addition, it is thought that the four members of the family form various heterodimers (Yarden and Sliwkowski 2001). In particular, ErbB2 and ErbB3 - which do not form homodimers (Ferguson et al. 2000; Cho et al. 2003; Berger et al. 2004) — signal only through heterodimerization (with one another and with other ErbB receptors). Following activation, a series of tyrosines in the carboxyterminal tail become autophosphorylated in trans (Honegger et al. 1989) and serve as "docking" sites for phosphotyrosine-binding $\mathrm{SH} 2$ and PTB domains as discussed in Wagner et al. (2013). Different ErbB family members harbor different complements of tyrosine phosphorylation sites in their carboxy-terminal tails (Lemmon and Schlessinger 1994; Yarden and Sliwkowski 2001; Jones et al. 2006), thus eliciting distinct but overlapping sets of responses.

\section{STRUCTURAL BASIS FOR LIGAND- INDUCED DIMERIZATION OF ErbB RECEPTORS}

A series of crystal structures published in 2002 and 2003 provided a dramatic leap forward in our understanding of transmembrane signaling by ErbB receptors (Burgess et al. 2003) and laid the foundation for much of our current understanding of how these receptors function. Structures of the EGFR extracellular region with and without bound growth factor provided a satisfying, and unexpected, model for ligandinduced receptor dimerization. They showed that - in contrast with other RTKs-dimerization of the EGFR extracellular region is mediated entirely by receptor-receptor contacts. With the exception of the insulin receptor, this makes EGFR and its relatives unique among the RTKs discussed in this collection. In all other cases that are understood, the activating growth factor ligand binds at the dimer interface, effectively serving to cross-link the two receptors into a dimer (Lemmon and Schlessinger 2010)—typ- ically with the aid of additional receptor-receptor contacts. As shown on the right side of Figure 2, the bound ligands in an EGFR dimer are as far as they possibly could be from the dimer interface (Garrett et al. 2002; Ogiso et al. 2002)—and, indeed, from one another. Each bound ligand is bivalent but simultaneously contacts two points (domains I and III) in the extracellular region of a single receptor molecule, rather than spanning two receptors. Domains I and III are rigid $\beta$-helix/solenoid structures that do not change conformation after ligand binding (Ferguson 2004). Dimerization is driven almost exclusively by a "dimerization arm" that projects from domain II, although inter-receptor domain IV contacts (Fig. 2A) may also contribute weakly (Dawson et al. 2005; Lu et al. 2010). Activation (by way of inducing dimerization) involves an unexpectedly large ligand-induced conformational change that exposes this domain II dimerization arm. In the absence of bound ligand, the EGFR, ErbB3, and ErbB4 extracellular regions form the "tethered" structure shown on the left side of Figure 2A, in which the domain II dimerization arm is buried by intramolecular interactions with domain IV (Cho and Leahy 2002; Ferguson et al. 2003; Bouyain et al. 2005). Ligand binding to domains I and III effectively pulls these domains together and "extends" the receptor's extracellular region to break the domain II/IV tether and expose the dimerization site-yielding a dimerization-competent ligand-bound EGFR extracellular region that self-associates strongly.

\section{ACTIVATION OF THE KINASE DOMAIN BY FORMATION OF AN ASYMMETRIC DIMER}

The first crystallographic view of the EGFR TKD (Stamos et al. 2002) confirmed previous reports that activation-loop phosphorylation is not required for it to adopt an active-like structure (Gotoh et al. 1992; Burgess et al. 2003) but provided little insight into how it is activated by receptor dimerization. The likely activation mechanism was revealed in 2006 through insightful analysis of additional crystal structures 
EGFR Family

A

Tethered

Extended
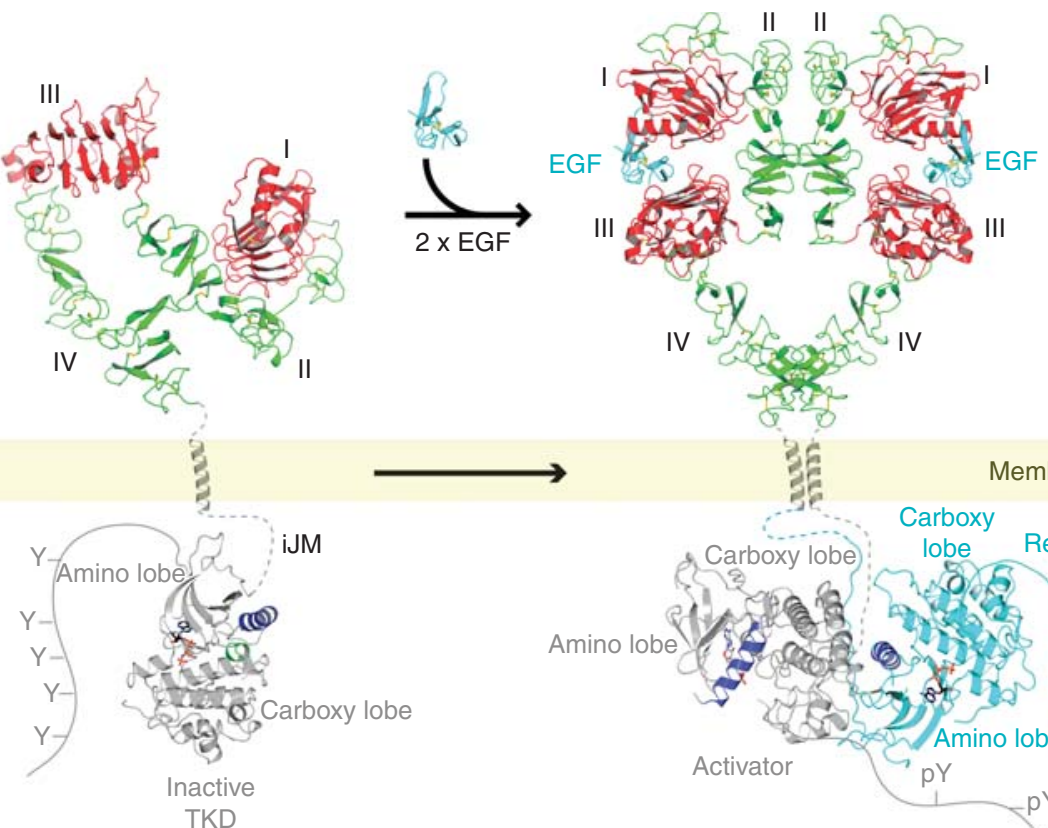

III
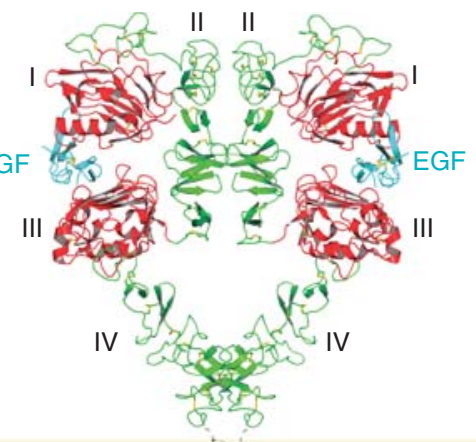

II II

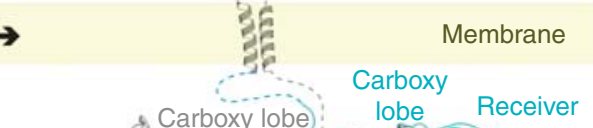

B
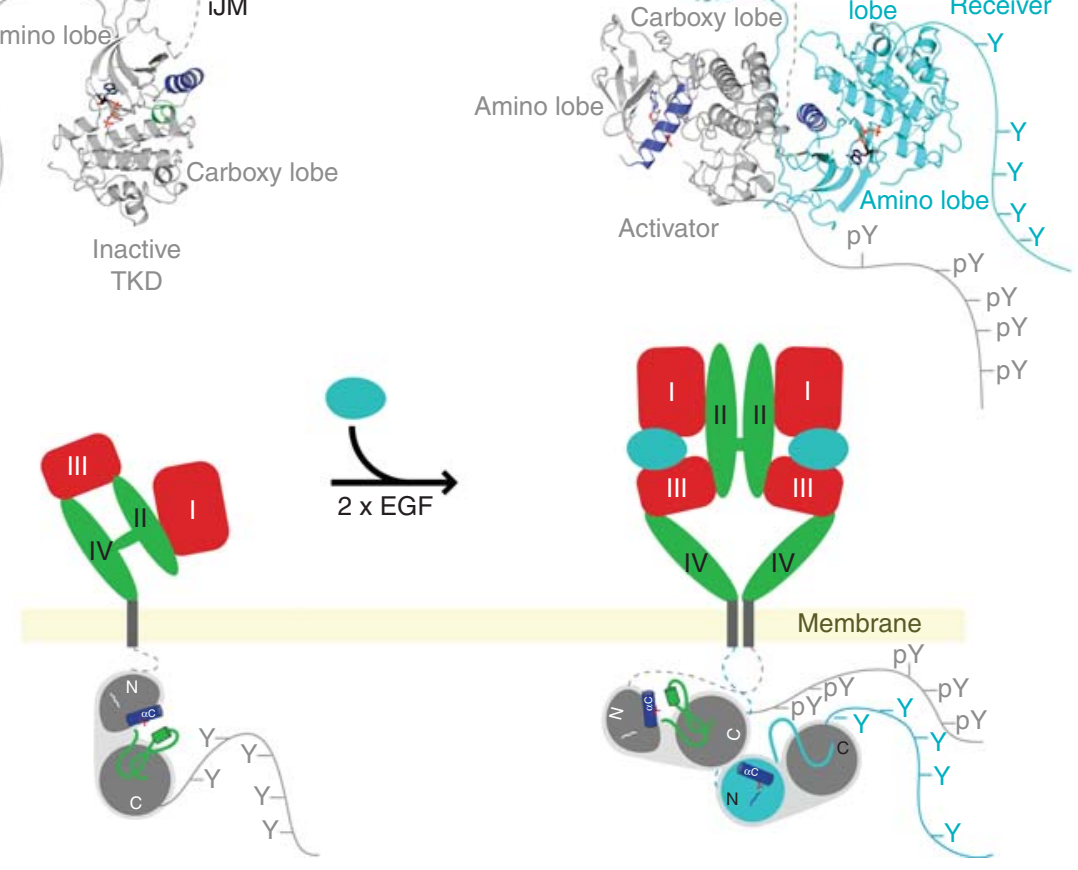
pry

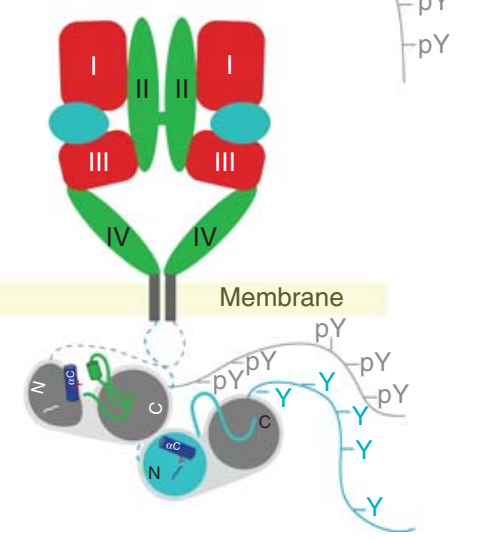

Figure 2. Basic model for EGF-induced dimerization and activation of EGFR. (A) In the absence of bound EGF, the human receptor is largely monomeric. The intracellular TKD is inactive, and the extracellular region adopts a "tethered" configuration in which a $\beta$-hairpin from domain II (the dimerization arm) forms intramolecular autoinhibitory interactions with domain IV. EGF binds to both domains I and III and induces a dramatic conformational change that "extends" the extracellular region and exposes the dimerization arm. With the domain II dimerization arm exposed, the EGFR extracellular region dimerizes (Burgess et al. 2003), bringing the intracellular TKDs into close proximity so that they can form the asymmetric dimer that leads to kinase activation (Zhang et al. 2006). In the asymmetric dimer, one TKD (gray) serves as the "activator," and the other (cyan) is the "receiver" that becomes allosterically activated and trans-phosphorylates tyrosines in the tail of the activator. (B) A cartoon representation of the structural changes shown in (A). (From Ferguson 2008; adapted, with permission, from the author.) 
M.A. Lemmon et al.

of the active EGFR TKD by the Kuriyan laboratory (Zhang et al. 2006). A characteristic asymmetric dimer was seen in the crystals used to solve each of these structures, in which the carboxy lobe of one TKD abuts the amino lobe of the other TKD, as depicted in the right-hand sides of Figure $2 \mathrm{~A}$ and $\mathrm{B}$. This relationship resembles that seen between cyclins and the amino lobe of the cyclin-dependent kinases (CDKs) that they activate, and the carboxy lobe of the "activator" kinase in an EGFR TKD dimer is thought to induce allosteric changes in the amino lobe of the "receiver" kinase and thus activate it. Analysis of a series of mutations in the asymmetric dimer interface confirmed its importance for activation of intact EGFR (Zhang et al. 2006), and subsequent studies showed that the NRG receptor ErbB4 is regulated in much the same way (Qiu et al. 2008).

These studies revealed that just as ErbB receptors are anything but prototypical RTKs in terms of their extracellular regulation, so are they unique in their intracellular regulation. Whereas activation-loop phosphorylation is a key step in regulating the TKDs of most RTKs (see Belov and Mohammadi 2013; Heldin and Lennartsson 2013; Hubbard 2013), it plays no part in the ErbB family (Gotoh et al. 1992; Burgess et al. 2003; Jura et al. 2011). Consistent with this distinction, the "inactive" conformation of ErbB family TKDs differs substantially from that seen in other RTKs (Wood et al. 2004; Zhang et al. 2006) and instead resembles inactive Src family kinases and CDKs. The model for allosteric activation of the EGFR TKD by its asymmetric dimerization following extracellular ligand binding provides a satisfying explanation for how this receptor can be regulated without activationloop phosphorylation. In brief, the carboxy lobe of the activator kinase interacts with the amino lobe of the receiver and induces several conformational changes in the receiver amino lobe (Fig. 3A,B). In particular, helix $\alpha \mathrm{H}$ of the activator interacts directly with helix $\alpha \mathrm{C}$ of the receiver, causing the $\alpha \mathrm{C}$ helix to rotate from its "out" position in the inactive EGFR TKD to the "in" position seen in active kinases. This movement disrupts interactions between the $\alpha \mathrm{C}$ helix and the short helix in the activation loop-freeing the activation loop to adopt the conformation typically seen in active kinases. In addition, rotation of helix $\alpha \mathrm{C}$ brings a key glutamate in this helix (E738 in mature receptor numbering) close to the side chain of lysine 721 , with which it can form a salt bridge to promote ATP binding. Thus, interaction with the carboxy lobe of the activator promotes an inactive-to-active conformational transition in the receiver TKD (Zhang et al. 2006), and the EGFR kinase is activated allosterically rather than through activation-loop phosphorylation. The models in Figures 2 and $3 \mathrm{~B}$ raise the question as to whether this is "vectorial," with only one EGFR becoming autophosphorylated in its carboxy-terminal tail. Presumably, however, the two molecules in the dimer dissociate and reassociate sufficiently rapidly that both can occupy the activator position (and thus be trans-autophosphorylated) for at least part of the time-although it should be noted that cis-autophosphorylation has not been formally excluded as a possibility.

\section{EGFR TKD MUTATIONS IN LUNG CANCER}

Importantly, the allosteric activation mechanism described above provides a satisfying explanation for the effects of oncogenic driver mutations in the EGFR TKD found in $\sim 10 \%$ of non-small-cell lung cancer patients (Sharma et al. 2007). These mutations were identified in 2004 in lung cancer patients who responded dramatically to the EGFR tyrosine kinase inhibitors (TKIs) erlotinib and gefitinib (Lynch et al. 2004; Paez et al. 2004; Pao et al. 2004). Many of these mutations - notably those at L834 and L837 (Fig. 3A)-occur at residues that stabilize "autoinhibitory" interactions in the inactive EGFR TKD. In particular, mutations such as L834R and L837Q disrupt autoinhibitory interactions between an $\alpha$-helix in the activation loop (green in Fig. 3A; seen only in the inactive TKD) and the $\alpha \mathrm{C}$ helix (blue in Fig. 3A) that hold the $\alpha \mathrm{C}$ helix away from the position that it adopts in the active kinase. When this autoinhibitory interaction is disrupted, the inactive TKD conformation is destabilized, leading to its constitutive activation and the acquisition of ligandindependent (oncogenic) signaling properties 
EGFR Family
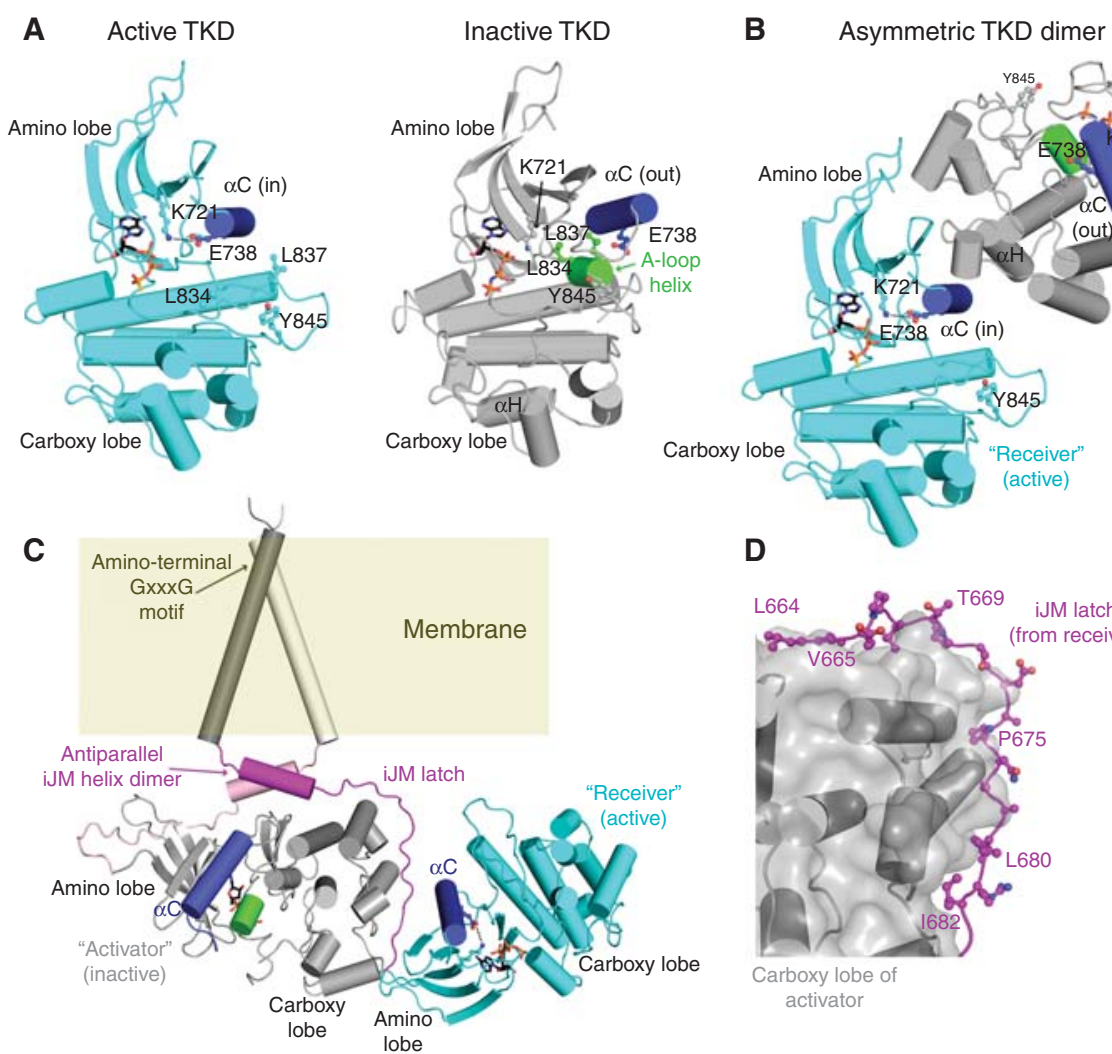

D
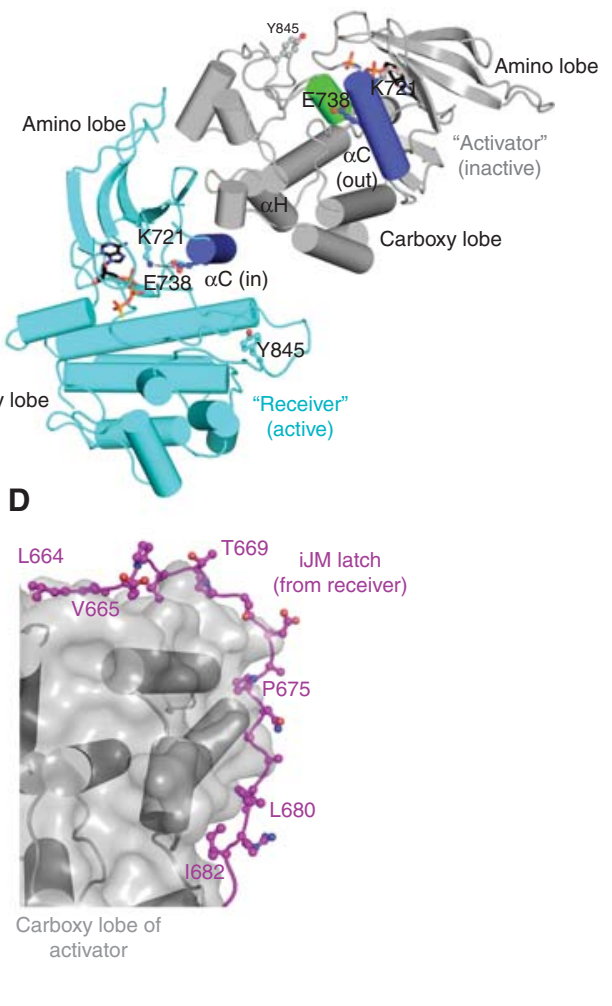

Figure 3. Intracellular EGFR activation. (A) EGFR TKD is shown in its active (left: PDB entry 2GS6) and inactive (right: PDB entry 2GS7) configurations (Zhang et al. 2006). The amino and carboxy lobes are marked, and the nucleotide moiety is shown in stick representation. The $\alpha \mathrm{C}$ helix (dark blue) occupies the "in" position in the active TKD and the "out" position in the inactive TKD. As a result, the E738 side chain is brought sufficiently close to the K721 side chain to form a salt bridge only in the active TKD. An additional short $\alpha$-helix forms in the activation loop only in the inactive TKD (green) and interacts with the $\alpha \mathrm{C}$ helix to promote its displacement. Mutations at two residues in this short A-loop helix (L834 and L837 in mature EGFR, L858 and L861 in proEGFR) are among the most common seen in EGFR-driven non-small-cell lung cancer (Sharma et al. 2007). Y845 (labeled) in the A-loop is equivalent to the key site of activating autophosphorylation in other RTKs, but its phosphorylation is not required for EGFR activation. (B) A model of an EGFR TKD asymmetric dimer, based on crystal packing in the 2GS6 structure (Zhang et al. 2006) in which an inactive TKD (from 2GS7) has been modeled in the activator position. The activator (gray) remains inactive in this discrete asymmetric dimer, and the receiver (cyan) becomes activated. $(C)$ The same asymmetric dimer shown in $(B)$ is shown linked to the TM domain based on a composite view of the TM and iJM structure derived from crystallographic, NMR, and computational studies (Jura et al. 2009a; Red Brewer et al. 2009; Endres et al. 2013). The TM domain forms a symmetric dimer mediated by its more amino-terminal GxxxG motif, and this, in turn, is thought to drive formation of an antiparallel dimer between helices in the amino-terminal part of the iJM region (magenta). The remainder of the iJM region in the receiver "cradles" the carboxy lobe of the activator to form the iJM "latch" that stabilizes the activating asymmetric dimer. The structure of the iJM latch region in the activator is not defined. $(D)$ Close-up view of the iJM latch cradling the carboxy lobe of the activator TKD. Mutations at L664, V665, P675, L680, I682, and other residues in the latch impair EGFR activation, and a V665M mutation is activating (Jura et al. 2009a; Red Brewer et al. 2009). 
M.A. Lemmon et al.

by the EGF receptor. Numerous structures of mutated EGFR TKD variants found in cancer patients have provided a rich understanding of how somatic mutations activate the receptor to become oncogenic drivers, as reviewed elsewhere (Eck and Yun 2010). Combined with biochemical analysis, these studies have also shown how secondary mutations can promote drug resistance and have provided important insight into the requirements for "next-generation" EGFR-targeted TKIs (Ohashi et al. 2013).

\section{PIECING TOGETHER INTACT ErbB RECEPTORS THROUGH EXPERIMENT}

\section{The Transmembrane (TM) Domain}

Although the models presented in Figures 2 and 3B likely capture many of the key interactions involved in EGFR regulation, they are clearly missing several important elements. For example, it has been known for some time that the single transmembrane (TM) domain of each ErbB family member self-associates in lipid membranes (Mendrola et al. 2002) through one or more GxxxG dimerization motifs (Lemmon et al. 1994). Cysteine cross-linking studies in cell membranes suggest that the two TM domains in an EGF-stimulated EGFR dimer contact one another in the more amino terminal of two GxxxG-motif regions (Lu et al. 2010). However, EGFR signaling appears to be highly resilient to mutations in the TM domain of the receptor when ligand-induced autophosphorylation is assessed in qualitative and semiquantitative studies (Kashles et al. 1988; Carpenter et al. 1991; Lu et al. 2010). Moreover, an EGFR variant with its TM domain replaced with polyleucine retains signaling activity in typical cellbased assays of this sort (JM Mendrola and MA Lemmon, unpubl.). Such observations led Springer and colleagues to argue that the intracellular and extracellular regions of EGFR are "loosely" linked (Lu et al. 2010)—and that no specific transmembrane (or extracellular juxtamembrane) interfaces are required for EGF-induced autophosphorylation of EGFR. However, more quantitative immunofluorescence-based studies of EGFR autophosphorylation have recently indicated that the TM domain contributes to EGFR dimerization (and activation). An NMR-guided structural model suggested that the EGFR TM region dimerizes through the more amino terminal of its two GxxxG motif regions (Endres et al. 2013), as shown in Figure 3C. Interestingly, this region has the sequence TGMVGA, which contains two overlapping G/smallxxxG/small motifs as defined (Russ and Engelman 2000): TxxxG and GxxxA. Consistent with structural "plasticity" in this region, no effect on EGFR signaling was seen if either GxxxG motif was mutated individually. Replacing all four "small" residues with isoleucines, however, thus disrupting both motifs, resulted in some $(\sim 50 \%)$ reduction in EGF-induced EGFR autophosphorylation (Endres et al. 2013).

\section{The Extracellular Juxtamembrane (eJM) Region}

There is relatively little information on the properties of, and interactions mediated by, the extracellular juxtamembrane (eJM) region of EGFR family members. This is a short stretch of polypeptide, with just seven amino acids separating the most carboxy-terminal residue of domain IV seen in crystal structures of the EGFR extracellular region (Ferguson et al. 2003; Lu et al. 2010) and the hydrophobic region of the TM domain. Cysteine cross-linking studies suggest that the eJM regions of the two receptors in an EGF-induced dimer come into close proximity, but do not indicate a specific or welldefined mode of association ( $\mathrm{Lu}$ et al. 2010). Intriguingly, however, inserting an additional flexible linker of 20-40 residues into this region appears to promote ligand-independent activation of EGFR (Sorokin 1995; Endres et al. 2013). This result might be taken to suggest that introducing flexibility between the extracellular and TM regions of EGFR leads to constitutive activation and/or that the spatial relationship between the extracellular region and the membrane is important. The eJM region of EGFR has also been suggested as the site of interaction with the ganglioside GM3, which inhibits 
allosteric activation of the receptor (Coskun et al. 2011). Mutation of a lysine in the middle of the seven-residue JM linker abolishes GM3's inhibitory effect.

Differences in the eJM region can profoundly affect ErbB receptor function. ErbB4 exists as two isoforms (JM-a and JM-b) that differ in their eJM region (Elenius et al. 1997). The JM-a isoform is cleaved extracellularly following NRG binding, and is then cleaved again to generate an intracellular soluble species that is translocated to the nucleus (see Carpenter and Liao 2013; Song et al. 2013). In contrast, the JM-b isoform functions only as a membranebound receptor. Similar variation is not seen for the other ErbB family members.

The Intracellular Juxtamembrane (iJM) Region

Recent work has shed important light on the intracellular JM (iJM) region of EGFR and its relatives. As with other aspects, increased understanding of the iJM region has shown EGFR to be anything but a prototype for other RTKs. Whereas most studies of RTK iJM regions have shown them to have an autoinhibitory role (Hubbard 2004), it is now clear that the iJM of EGFR has a key positive role in receptor activation. This observation was first reported by Graham Carpenter's laboratory (Thiel and Carpenter 2007). They found that an intact iJM region is required for EGF-induced autophosphorylation of EGFR and is primarily required in the "receiver" kinase shown in Figures 2 and 3B. Subsequent alanine-scanning mutagenesis studies defined an activation domain in the iJM region (Red Brewer et al. 2009), extending from L664 to I682. Residues G672-I682 were already known to lie in the "amino-terminal extension” of the EGFR TKD (Zhang et al. 2006) and to play a key part in the asymmetric dimer interface that is responsible for EGFR activation. Mutating residues 675,680 , or 682 in this region disrupts the asymmetric dimer (Zhang et al. 2006). Crystallographic studies of an EGFR TKD variant containing the complete iJM showed that, in the asymmetric dimer, a region beyond the amino-terminal extension of the receiver TKD "cradles" the carboxy lobe of the activator (Fig. 3C,D), apparently stabilizing asymmetric interactions between the two TKDs (Red Brewer et al. 2009). A similar arrangement was also reported in asymmetric ErbB4 TKD dimers (Wood et al. 2008). Based on these structures, residues 664-672 are considered to constitute a "juxtamembrane latch" (Jura et al. 2009a), enhancing EGFR activation by promoting formation of the asymmetric dimer. Interestingly, phosphorylation of a threonine (T669) in the juxtamembrane latch (by MAP kinase) modulates EGFR activation and downregulation (Morrison et al. 1993; Li et al. 2008), and mutation of V665 to methionine-which would be predicted to strengthen the latch (Fig. 3D) - appears to be an oncogenic driver mutation in non-small-cell lung cancer (Red Brewer et al. 2009).

The juxtamembrane latch constitutes about half of the iJM region of EGFR and is preceded by an $\alpha$-helix that extends from T654, an inhibitory PKC site (Welsh et al. 1991), to L664 (Red Brewer et al. 2009). Deletion of this region-even when the juxtamembrane latch is intact-impairs EGFR activation (Thiel and Carpenter 2007; Jura et al. 2009a). Intriguingly, this region appears to form an antiparallel helical dimer in the NMR-guided structural model of the TM domain plus iJM helix in Figure 3C (Endres et al. 2013). A chemical biology approach using bipartite tetracysteine display has also provided evidence for formation of this antiparallel helical dimer in the intact receptor in cells (Scheck et al. 2012). Formation of such a dimer offers a way to break the artifactual "daisy chain" seen in crystals of the isolated EGFR TKD, in which the iJM region of each molecule cradles the carboxy lobe of its neighbor, and each TKD simultaneously acts as activator and receiver. As shown in the hypothetical model presented in Figure 3C, the TM-domain dimer appears to promote antiparallel association of the iJM helices of two TKDs. Formation of this dimer displaces the remainder of the iJM in the activator TKD to break the daisy chain seen in crystals while allowing the iJM of the receiver to function as the juxtamembrane latch shown in Figure 3C,D. 
M.A. Lemmon et al.

The models described above, and depicted in Figure 3, consider the TM and JM regions in only the activated EGFR. By analogy with the extracellular region and TKD, however, it is likely that these are subject to autoinhibitory interactions in the absence of ligand. Indeed, the second GxxxG motif in the TM domain may offer an alternative mode of TM packing in much-discussed preformed dimers of EGFR, which has been proposed to be autoinhibitory (Endres et al. 2013). Reorientation of the extracellular regions after ligand binding is presumed to disrupt these putative autoinhibitory TMdomain interactions. Turning attention to the iJM region, McLaughlin and colleagues (2005) made an intriguing proposal that EGFR autoinhibition involves binding of both a basic region within the iJM (including the iJM $\alpha$-helix) and a basic patch on the TKD surface to anionic phospholipids in the plasma membrane inner leaflet. They showed that a peptide corresponding to the amino-terminal iJM region (residues 645-660) binds strongly to negatively charged membrane surfaces. Although they initially suggested that calmodulin binding to the iJM region might dissociate it from the membrane (and thus activate EGFR), more recent NMR studies have suggested that TM-domain dimerization or reorientation may be sufficient to dissociate the iJM region from the membrane, presumably by stabilizing the antiparallel $\alpha$-helix dimer shown in Figure 3C (Matsushita et al. 2013). These possibilities clearly need further investigation in the context of the intact receptor.

\section{The Carboxy-Terminal Tail}

The $\sim 230$-amino-acid carboxy-terminal tail of EGFR (residues 956-1186) and its relatives accounts for $\sim 20 \%$ of the receptor molecule. This region contains all of the known autophosphorylation sites in EGFR (except Y845 in the TKD) but is poorly characterized and is generally viewed as an unstructured region to which multiple SH2 domains bind (Gajiwala 2013). Fluorescence anisotropy and fluorescense resonance energy transfer (FRET) studies have clearly shown changes in the conformation and dynamics of the EGFR carboxy-terminal tail after autophosphorylation (Lee and Koland 2005; Lee et al. 2006b). Moreover, truncation mutants in this region have shown altered kinase activity toward cellular substrates, leading to the suggestion that some regions within the carboxy-terminal tail function as autoinhibitory domains (requiring tyrosine phosphorylation to release the inhibition) and others as positive modulators of activity (Walton et al. 1990; Alvarez et al. 1995). A regulatory function for the region of the carboxy-terminal tail closest to the kinase domain is also supported by crystallographic studies. A structure of EGFR TKD in its inactive conformation (Wood et al. 2004) showed two TKD-proximal regions of the carboxy-terminal tail packed against the amino lobe of the kinase in the manner expected if they were to play an autoinhibitory part (Fig. 4A). Residues 971-980 form a short $\alpha$-helix that lies adjacent to the hinge region between the TKD amino and carboxy lobes. Residues 986-994 form another partly helical region that contacts elements of strands $\beta 3-\beta 5$ in the TKD amino lobe. Interestingly, Y992 (a known major autophosphorylation site in EGFR) and Y974 (at which EGF-induced phosphorylation promotes endocytosis) (Tong et al. 2009) are positioned to stabilize these potentially autoinhibitory intramolecular interactions. The short helix that contains Y992 was also seen in a very similar location and orientation in another crystal structure of inactive EGFR TKD (Zhang et al. 2006) but is also seen (only slightly shifted) in many active EGFR TKD structures (Fig. 4B). In a symmetric dimer of inactive EGFR TKD (Jura et al. 2009a), the intramolecularly associated 986-994 helix is replaced by a longer helix (with the opposite orientation) involving residues 967-978 of a neighboring molecule. Several other locations and orientations of these regions of the carboxy-terminal EGFR TKD tail have now been seen in other crystal structures (Gajiwala 2013). Although a self-consistent picture of the mechanism of autoinhibition by the carboxy-terminal tail (and how it might be reversed by autophosphorylation) has yet to emerge, it seems highly likely that these interactions involving the carboxy-terminal tail represent an additional important regulatory element. 
EGFR Family

A

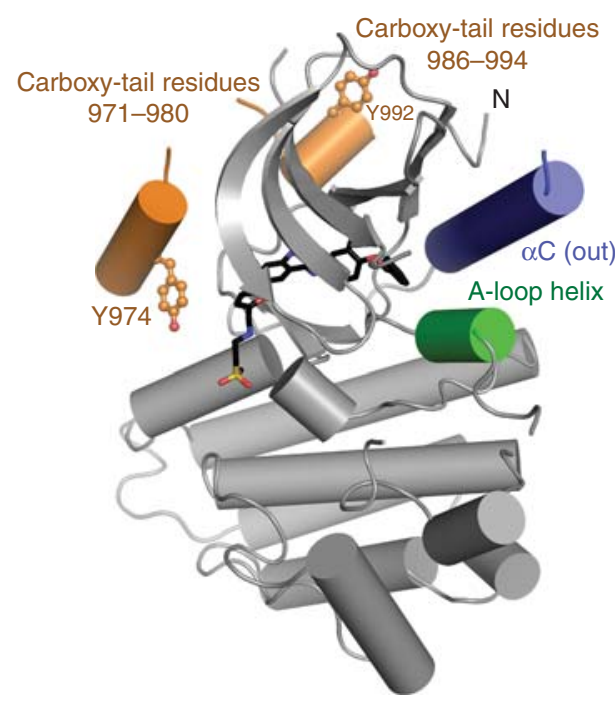

Inactive
B

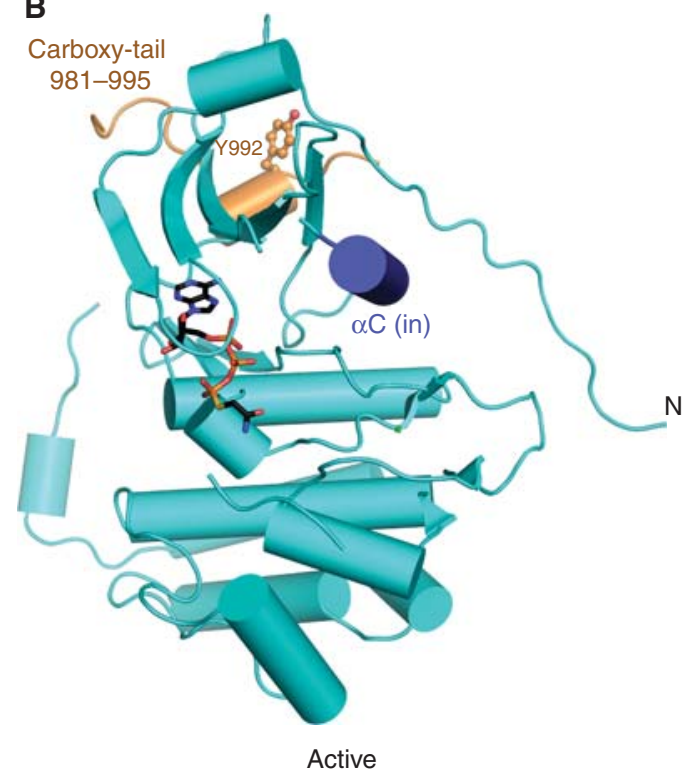

Figure 4. Location of the small section of the EGFR carboxy-terminal tail with known structure. $(A)$ A structure of the inactive EGFR TKD (PDB entry 1XKK) shows that two TKD-proximal regions of the carboxy-terminal tail form short helices (colored orange) that pack against the amino lobe as described in the text. Tyrosines 974 and 992 are marked, phosphorylation of which could be involved in EGFR regulation. (B) Structures of the active EGFR TKD, including this one (PDB entry 2GS6), also show the 986-994 region, including Y992, in a similar location-although not the 971-980 helix.

\section{TOWARD AN UNDERSTANDING OF THE INTACT EGF RECEPTOR}

Negative Cooperativity

Although initially satisfying, the basic model presented in Figure 2 for EGFR activation fails to explain several long-standing observations about the receptor-despite the additional complexity added by studies of the JM, TM, and carboxy-terminal tail regions. In particular, as pointed out as the first structures were solved (Burgess et al. 2003), this model fails to capture key qualitative features of EGF binding to the cell surface. As described by Schlessinger (2014), EGFR and the insulin receptor were the first RTKs for which cell-surface ligand binding was analyzed in detail, in the 1970s. Concave-up Scatchard plots were seen in both cases, indicating either heterogeneity of sites or negative cooperativity. In the case of insulin, further experiments showed the binding to be negatively cooperative (De Meyts 2008). For EGFR, in contrast, heterogeneity of sites was generally assumed, and a great deal of effort was put into understanding the difference(s) between the high- and low-affinity EGF-binding sites (Wofsy et al. 1992; Burgess et al. 2003; Klein et al. 2004) — with the former considered to be the site relevant for cell signaling. More recently, Pike and colleagues (Macdonald and Pike 2008) provided convincing evidence for negative cooperativity in EGF binding to its receptor from experiments in which they globally fit binding data obtained using cells expressing EGFR at a range of different levels. Negative cooperativity (and the characteristic concave-up Scatchards) is seen only for the intact receptor. Deletion of the cytoplasmic domain from EGFR appears to abolish negative cooperativity (Livneh et al. 1986), and further analysis has placed particular emphasis on interactions that involve the iJM region (Macdonald-Obermann and Pike 2009). As is the case with the insulin receptor (De Meyts 2008), negative cooperativity is not observed in 
M.A. Lemmon et al.

studies of the soluble extracellular region of the human EGF receptor. The EGFR extracellular region forms a 1:1 complex with EGF $\left(K_{D} \sim\right.$ $400 \mathrm{nM}$ ) that subsequently dimerizes (with $K_{D}$ $\sim 3 \mu \mathrm{M})$ to form a 2:2 EGF:EGFR complex (Lemmon et al. 1997) with no significant cooperativity. Interactions involving the intracellular and iJM regions are clearly required for occupation of one binding site in an EGFR dimer to influence binding to the other in negative cooperativity.

Studies of the D. melanogaster EGFR (dEGFR) have provided a structural view of how negative cooperativity can arise in ligand binding to a member of the ErbB family (Alvarado et al. 2010). Unlike its human counterpart, dEGFR retains negative cooperativity in ligand binding when the soluble (overexpressed) extracellular region is studied. This protein can also be crystallized as an asymmetric singly ligated extracellular dimer that suggests a straightforward explanation for half-of-the-sites negative cooperativity (Levitzki et al. 1971), as summarized in Figure 5. Intriguingly, dEGFR crystallizes as a dimer even when not bound to ligand (Alvarado et al. 2009), providing a potential structural model for the preformed dimers of EGFR that have been reported in many studies (discussed in Valley et al. 2014 and ArndtJovin et al. 2014). This dimer also forms in solution (albeit weakly) and is mediated by the dimerization arm mentioned above. The scheme shown in Figure 5 is based on actual crystal structures. In the absence of ligand, all binding sites are equivalent (as monomers or in symmetric preformed dimers). Upon binding to the left-hand molecule in Figure 5, the Spitz ligand (cyan) "wedges" itself between domains I and III and forces them apart. As a result, domain II (which connects domains I and III) becomes bent and is forced up against domain II from the right-hand molecule, with which it makes a large number of new interactions. The extent of the dimer interface is thus increased substantially in the asymmetric dimer seen in the middle of Figure 5-consistent with the observed ligand-induced dimerization (Alvarado et al. 2010). Importantly, the new asymmetric dimer interface imposes restraints on the right-hand binding site of the dimer. When a second ligand binds to the dimer, it cannot push domains I and III apart without compromising the asymmetric dimer interface. Indeed, asymmetry is retained in a 2:2 ligand:receptor complex (rightmost structure in Fig. 5), and the second ligand forms a compromised set of interactions consistent with its lower affinity. Thus, binding of the first ligand to a symmetric dimer imposes an asymmetry that reduces the binding affinity of the second ligand in an example of classic half-of-the-sites negative cooperativity (Levitzki et al. 1971; Alvarado et al. 2010).

Negative cooperativity provides a potential mechanism for graded activation of EGFR in response to a concentration gradient of activating ligand (as morphogen), known to be important in several contexts for Spitz and EGFR in D. melanogaster (Golembo et al. 1996). It is also likely to be relevant in mammals. Although a singly ligated asymmetric dimer has not been seen for a mammalian ErbB receptor extracellular region, detailed comparison of crystal structures of ligand-bound EGFR and ErbB4 extracellular dimers (Liu et al. 2012) provides compelling arguments that the model shown in Figure 5 is also relevant for human receptors. Moreover, by coexpressing mutated ErbB receptors with defects in ligand binding and kinase activity, respectively, the Leahy laboratory has provided evidence that singly ligated dimers of EGFR and ErbB4 are competent to signal (Liu et al. 2012).

\section{Linkage between Extracellular and Intracellular Regions}

As described above, there is now clear evidence for formation of asymmetric dimers in both the extracellular and intracellular regions of EGFR, raising the question of how the two are linked. It would seem reasonable to argue that asymmetry in the extracellular region might promote asymmetry in the intracellular region in a welldefined way, suggesting a view of intact ErbB receptors as allosterically regulated dimeric enzymes with a dimer interface that happens to span the membrane (Lemmon 2009). Experi- 

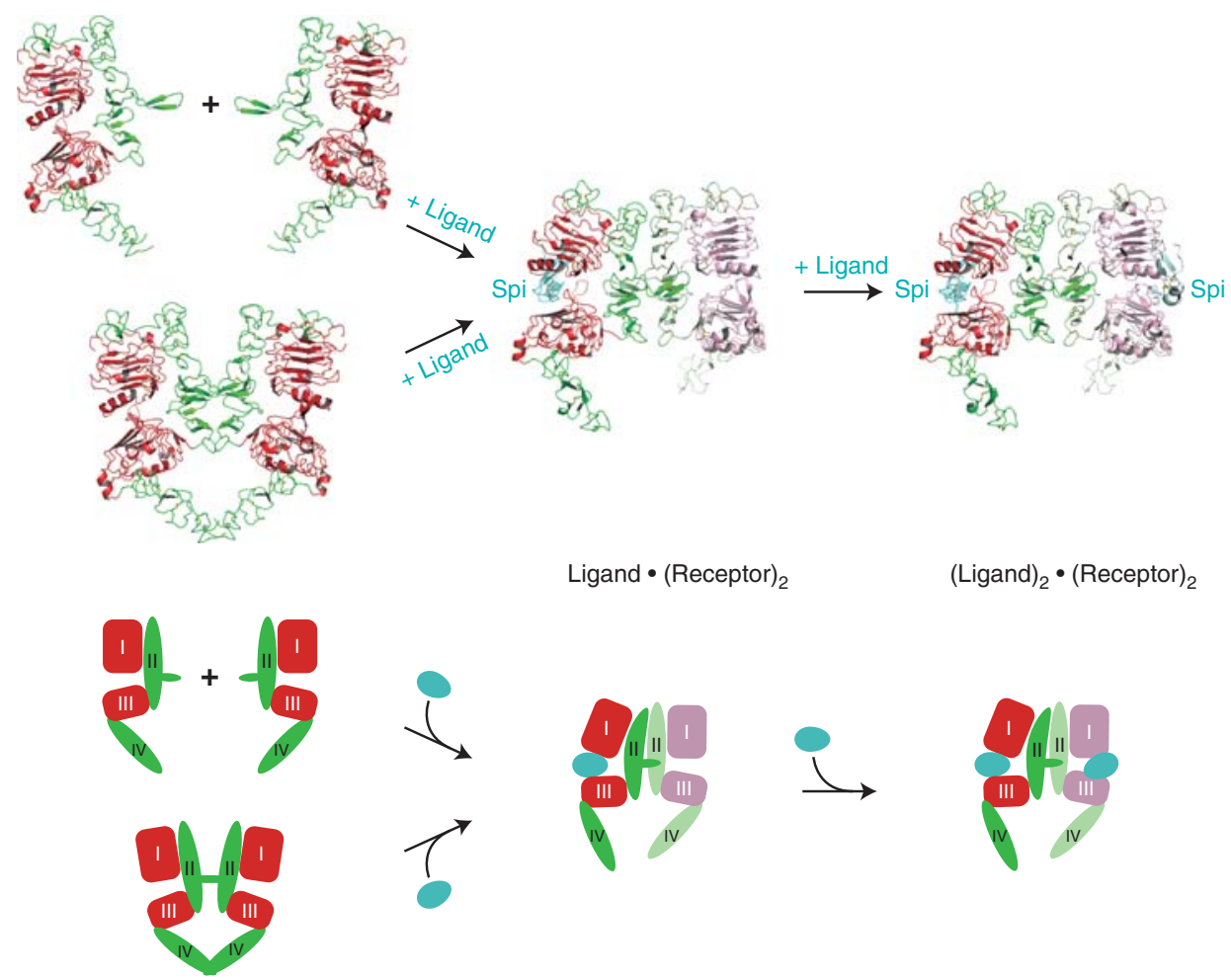

Figure 5. Structural basis for negative cooperativity in an EGF receptor. Negatively cooperative ligand binding is retained by the isolated extracellular region of the D. melanogaster EGFR, which binds to the EGF homolog Spitz (Spi), whereas it is lost in studies of the human receptor. Crystallographic studies have revealed the structural basis for this negative cooperativity. The D. melanogaster EGFR extracellular region does not form the tethered structure depicted in Figure 2A, remaining as an untethered monomer or forming a symmetric (crystallographic) dimer even in the absence of bound ligand (Alvarado et al. 2009). After binding of ligand to the left-hand molecule in the symmetric dimer, domains I and III are wedged apart as described in the text so that domain II of the left-hand molecule "collapses" onto its counterpart in the right-hand molecule. The result is a singly ligated asymmetric dimer. This transition restrains the second ligand-binding site so that the wedging apart of domains I and III is disfavored, reducing the affinity of ligand for the second site-resulting in negative cooperativity. The structures in the upper panel are actual crystal structures (PDB entries 3I2T, 3LTG, and 3LTF) and are redrawn as cartoons in the lower part of the figure for clarity (Alvarado et al. 2009, 2010).

mental studies with intact receptors, however, give quite different impressions. As mentioned above, cysteine cross-linking studies in the Springer laboratory (Lu et al. 2010) suggested that the extracellular and intracellular regions of EGFR in cell membranes are only loosely linked. Negative-stain electron microscopy studies of nearly intact EGFR provide a similar impression, suggesting that even with a single dimeric configuration of the EGFR extracellular region, the intracellular region of the same molecule is free to adopt a range of different confor- mations (Mi et al. 2011). Moreover, in studying signaling by singly ligated EGFR and ErbB4 dimers, Liu et al. (2012) reported that the part of "activator" in the intracellular asymmetric TKD dimer could be played by either the ligand-bound or the ligand-free receptor-again suggesting flexibility or plasticity. In contrast, other studies using mutated receptors have suggested that the extracellular asymmetry in an EGFR/ErbB2 heterodimer is strictly maintained in the intracellular region (MacdonaldObermann et al. 2012)—with the EGFR TKD 
M.A. Lemmon et al.

obligately adopting the receiver position and being activated first.

A flexible linkage between the extra- and intracellular regions of EGFR family members would certainly be sufficient for a signaling mechanism involving straightforward ligandinduced receptor dimerization. It is difficult, however, to understand how preformed receptor dimers could be regulated by ligand binding (Chung et al. 2010) without rigid coupling of extra- and intracellular conformations. Moreover, it seems unlikely that intracellular mutations or deletions in EGFR (or T654 phosphorylation) would be able to influence the cooperativity of extracellular ligand binding (Macdonald-Obermann and Pike 2009) if intra/extracellular linkage is loose. In addition, is not clear how the different ligands that bind to a given ErbB family member could induce the distinct signaling responses that have been reported (Wilson et al. 2009) if the extraand intracellular regions were flexibly linkedand there would be no basis for expecting distinct signaling by singly and doubly ligated receptor dimers. Interpreting studies of purified intact ErbB receptors is made difficult by the need to recapitulate the correct membrane environment-including acidic phospholipids and possibly gangliosides-and its asymmetry in order to be sure that the extracellular and intracellular (and, more importantly, the JM) regions are placed in physiologically relevant contexts. Cellular studies are inherently less detailed and quantitative, and-for negatively cooperative systems - it is difficult to be certain that a single receptor conformation is being studied (rather than a mixture of singly and doubly ligated dimers, for example). As discussed elsewhere, however, technologies for studying intact receptors in cells are improving greatly and will soon be at the stage where cellular and structural studies can be productively linked.

\section{CONCLUDING REMARKS}

Once considered prototypical RTKs, it is now clear that the EGFR and its relatives are actually quite unique in their properties. Our understanding of their regulation is now quite sophis- ticated, with multiple structures of extracellular regions and TKDs, and a growing knowledge of the JM and TM regions. Mechanistic studies have provided clear explanations for how oncogenic mutations in the TKD activate EGFR in non-small-cell lung cancer and have aided development of next-generation kinase inhibitors to combat resistance to existing agents. Advances in our understanding of extracellular regulation also promise to explain EGFR mutations in glioblastoma in the future (Lee et al. 2006a; Vivanco et al. 2012). EGFR family members are the only RTKs with a TKD that are regulated without requiring activation-loop phosphorylation-instead using a unique mode of allosteric regulation through asymmetric dimerization. EGFR is also the only well-understood RTK in which bound ligand does not contribute directly to the dimer interface-instead controlling receptor-mediated dimerization. The EGFR family shares more similarities with the insulin receptor than with most other RTKsincluding negative cooperativity in its ligand binding, which may reflect its function as a detector of ligand concentration in morphogen gradients. One of the next frontiers in understanding EGFR family signaling will be detailed studies of intact receptors - so that the JM regions can be studied in physiologically (and structurally) relevant environments. Another will be thorough investigation of how the flexible carboxy-terminal tail contributes to EGFR regulation and coupling to downstream signaling. Given the plethora of ErbB family ligands and the wide range of processes in which ErbB receptors participate, it will also be important to relate signaling outcomes to specific ligands (or concentrations of ligands) to unravel the complicated biology of these receptors.

\section{REFERENCES}

${ }^{*}$ Reference is also in this collection

* Adrain C, Freeman M. 2014. Regulation of receptor tyrosine kinase ligand processing. Cold Spring Harb Perspect Biol doi: 10.1101/cshperspect.a008995.

Alvarado D, Klein DE, Lemmon MA. 2009. ErbB2 resembles an autoinhibited invertebrate epidermal growth factor receptor. Nature 461: 287-291. 
Alvarado D, Klein DE, Lemmon MA. 2010. Structural basis for negative cooperativity in growth factor binding to an EGF receptor. Cell 142: 568-579.

Alvarez CV, Shon KJ, Miloso M, Beguinot L. 1995. Structural requirements of the epidermal growth factor receptor for tyrosine phosphorylation of eps8 and eps15, substrates lacking Src SH2 homology domains. J Biol Chem 270: 16271-16276.

* Arndt-Jovin DJ, Botelho MG, Jovin TM. 2014. Structurefunction relationships of ErbB RTKs in the plasma membranes of living cells. Cold Spring Harb Perspect Biol doi: 10.1101/cshperspect.a008961.

Arteaga CL. 2003. ErbB-targeted therapeutic approaches in human cancer. Exp Cell Res 284: 122-130.

Arteaga CL, Sliwkowski MX, Osborne CK, Perez EA, Puglisi F, Gianni L. 2011. Treatment of HER2-positive breast cancer: Current status and future perspectives. Nat Rev Clin Oncol 9: 16-32.

* Belov AA, Mohammadi M. 2013. Advances in the molecular mechanisms of FGF signaling in physiology and pathology. Cold Spring Harb Perspect Biol 5: 015958.

Berger MB, Mendrola JM, Lemmon MA. 2004. ErbB3/ HER3 does not homodimerize upon neuregulin binding at the cell surface. FEBS Letts 569: 332-336,

Birchmeier C. 2009. ErbB receptors and the development of the nervous system. Exp Cell Res 315: 611-618.

Bouyain S, Longo PA, Li S, Ferguson KM, Leahy DJ. 2005. The extracellular region of ErbB4 adopts a tethered conformation in the absence of ligand. Proc Natl Acad Sci 102: 15024-15029.

Buonanno A, Fischbach GD. 2001. Neuregulin and ErbB receptor signaling pathways in the nervous system. Curr Opin Neurobiol 11: 287-296.

Burgess AW. 2008. EGFR family: Structure physiology signalling and therapeutic targets. Growth Factors 26: $263-$ 274.

Burgess AW, Cho HS, Eigenbrot C, Ferguson KM, Garrett TP, Leahy DJ, Lemmon MA, Sliwkowski MX, Ward CW, Yokoyama S. 2003. An open-and-shut case? Recent insights into the activation of EGF/ErbB receptors. Mol Cell 12: $541-552$.

* Carpenter G, Liao H-J. 2013. Receptor tyrosine kinases in the nucleus. Cold Spring Harb Perspect Biol doi: 10.1101/ cshperspect.a008979.

Carpenter CD, Ingraham HA, Cochet C, Walton GM, Lazar CS, Sowadski JM, Rosenfeld MG, Gill GN. 1991. Structural analysis of the transmembrane domain of the epidermal growth factor receptor. J Biol Chem 266: 57505755.

Cho HS, Leahy DJ. 2002. Structure of the extracellular region of HER3 reveals an interdomain tether. Science 297: $1330-1333$.

Cho HS, Mason K, Ramyar KX, Stanley AM, Gabelli SB, Denney DW Jr, Leahy DJ. 2003. Structure of the extracellular region of HER2 alone and in complex with the Herceptin Fab. Nature 421: 756-760.

Chung I, Akita R, Vandlen R, Toomre D, Schlessinger J, Mellman I. 2010. Spatial control of EGF receptor activation by reversible dimerization on living cells. Nature 464: $783-787$.
Coskun Ü, Grzybek M, Drechsel D, Simons K. 2011. Regulation of human EGF receptor by lipids. Proc Natl Acad Sci 108: 9044-9048.

Dawson JP, Berger MB, Lin CC, Schlessinger J, Lemmon MA, Ferguson KM. 2005. Epidermal growth factor receptor dimerization and activation require ligand-induced conformational changes in the dimer interface. $\mathrm{Mol}$ Cell Biol 25: 7734-7742.

De Meyts P. 2008. The insulin receptor: A prototype for dimeric, allosteric membrane receptors? Trends Biochem Sci 33: 376-384.

Eck MJ, Yun CH. 2010. Structural and mechanistic underpinnings of the differential drug sensitivity of EGFR mutations in non-small cell lung cancer. Biochim Biophys Acta 1804: 559-566.

Elenius K, Corfas G, Paul S, Choi CJ, Rio C, Plowman GD, Klagsbrun M. 1997. A novel juxtamembrane domain isoform of HER4/ErbB4. Isoform-specific tissue distribution and differential processing in response to phorbol ester. J Biol Chem 272: 26761-26768.

Endres NF, Das R, Smith AW, Arkhipov A, Kovacs E, Huang Y, Pelton JG, Shan Y, Shaw DE, Wemmer DE, et al. 2013. Conformational coupling across the plasma membrane in activation of the EGF receptor. Cell 152: 543-556.

Falls DL. 2003. Neuregulins: Functions, forms, and signaling strategies. Exp Cell Res 284: 14-30.

Ferguson KM. 2004. Active and inactive conformations of the epidermal growth factor receptor. Biochem Soc Trans 32: $742-745$.

Ferguson KM. 2008. Structure-based view of epidermal growth factor receptor regulation. Annu Rev Biophys 37: 353-373.

Ferguson KM, Darling PJ, Mohan MJ, Macatee TL, Lemmon MA. 2000. Extracellular domains drive homo- but not hetero-dimerization of erbB receptors. EMBO J 19: 4632-4643.

Ferguson KM, Berger MB, Mendrola JM, Cho HS, Leahy DJ, Lemmon MA. 2003. EGF activates its receptor by removing interactions that autoinhibit ectodomain dimerization. Mol Cell 11: 507-517.

Fiske WH, Threadgill D, Coffey RJ. 2009. ERBBs in the gastrointestinal tract: Recent progress and new perspectives. Exp Cell Res 315: 583-601.

Gajiwala KS. 2013. EGFR: Tale of the C-terminal tail. Prot Sci 22: 995-999.

Garrett TP, McKern NM, Lou M, Elleman TC, Adams TE, Lovrecz GO, Zhu HJ, Walker F, Frenkel MJ, Hoyne PA, et al. 2002. Crystal structure of a truncated epidermal growth factor receptor extracellular domain bound to transforming growth factor $\alpha$. Cell 110: 763-773.

Golembo M, Raz E, Shilo BZ. 1996. The Drosophila embryonic midline is the site of Spitz processing, and induces activation of the EGF receptor in the ventral ectoderm. Development 122: 3363-3370.

Gotoh N, Tojo A, Hino M, Yazaki Y, Shibuya M. 1992. A highly conserved tyrosine residue at codon 845 within the kinase domain is not required for the transforming activity of human epidermal growth factor receptor. Biochem Biophys Res Commun 186: 768-774.

Harris RC, Chung E, Coffey RJ. 2003. EGF receptor ligands. Exp Cell Res 284: 2-13. 
M.A. Lemmon et al.

* Heldin C-H, Lennartsson J. 2013. Structural and functional properties of platelet-derived growth factor and stem cell factor receptors. Cold Spring Harb Perspect Biol 5: a009100.

Honegger AM, Kris RM, Ullrich A, Schlessinger J. 1989. Evidence that autophosphorylation of solubilized receptors for epidermal growth factor is mediated by intermolecular cross-phosphorylation. Proc Natl Acad Sci 86: 925-929.

Hubbard SR. 2004. Juxtamembrane autoinhibition in receptor tyrosine kinases. Nat Rev Mol Cell Biol 5: 464-471.

* Hubbard SR. 2013. The insulin receptor: Both a prototypical and a typical receptor tyrosine kinase. Cold Spring Harb Perspect Biol 5: a008946.

Jones RB, Gordus A, Krall JA, MacBeath G. 2006. A quantitative protein interaction network for the ErbB receptors using protein microarrays. Nature 439: 168-174.

Jura N, Endres NF, Engel K, Deindl S, Das R, Lamers MH, Wemmer DE, Zhang X, Kuriyan J. 2009a. Mechanism for activation of the EGF receptor catalytic domain by the juxtamembrane segment. Cell 137: 1293-1307.

Jura N, Shan Y, Cao X, Shaw DE, Kuriyan J. 2009b. Structural analysis of the catalytically inactive kinase domain of the human EGF receptor 3. Proc Natl Acad Sci 106: 21608 21613.

Jura N, Zhang X, Endres NF, Seeliger MA, Schindler T, Kuriyan J. 2011. Catalytic control in the EGF receptor and its connection to general kinase regulatory mechanisms. Mol Cell 42: 9-22.

Kashles O, Szapary D, Bellot F, Ullrich A, Schlessinger J, Schmidt A. 1988. Ligand-induced stimulation of epidermal growth factor receptor mutants with altered transmembrane regions. Proc Natl Acad Sci 85: 9567-9571.

Klein P, Mattoon D, Lemmon MA, Schlessinger J. 2004. A structure-based model for ligand binding and dimerization of EGF receptors. Proc Natl Acad Sci 101: 929-934.

Lee NY, Koland JG. 2005. Conformational changes accompany phosphorylation of the epidermal growth factor receptor C-terminal domain. Prot Sci 14: 2793-2803.

Lee JC, Vivanco I, Beroukhim R, Huang JH, Feng WL, DeBiasi RM, Yoshimoto K, King JC, Nghiemphu P, Yuza Y et al. 2006a. Epidermal growth factor receptor activation in glioblastoma through novel missense mutations in the extracellular domain. PLoS Med 3: e485.

Lee NY, Hazlett TL, Koland JG. 2006b. Structure and dynamics of the epidermal growth factor receptor C-terminal phosphorylation domain. Prot Sci 15: 1142-1152.

Lemmon MA. 2009. Ligand-induced ErbB receptor dimerization. Exp Cell Res 315: 638-648.

Lemmon MA, Schlessinger J. 1994. Regulation of signal transduction and signal diversity by receptor oligomerization. Trends Biochem Sci 19: 459-463.

Lemmon MA, Schlessinger J. 2010. Cell signaling by receptor tyrosine kinases. Cell 141: 1117-1134.

Lemmon MA, Treutlein HR, Adams PD, Brünger AT, Engelman DM. 1994. A dimerization motif for transmembrane $\alpha$-helices. Nat Struct Biol 1: 157-163.

Lemmon MA, Bu Z, Ladbury JE, Zhou M, Pinchasi D, Lax I, Engelman DM, Schlessinger J. 1997. Two EGF molecules contribute additively to stabilization of the EGFR dimer. EMBO J 16: 281-294.
Levitzki A, Stallcup WB, Koshland DE Jr. 1971. Half-of-thesites reactivity and the conformational states of cytidine triphosphate synthetase. Biochemistry 10: 3371-3378.

Li X, Huang Y, Jiang J, Frank SJ. 2008. ERK-dependent threonine phosphorylation of EGF receptor modulates receptor downregulation and signaling. Cell Signal 20: 2145 2155.

Libermann TA, Nusbaum HR, Razon N, Kris R, Lax I, Soreq $\mathrm{H}$, Whittle N, Waterfield MD, Ullrich A, Schlessinger J. 1985. Amplification, enhanced expression and possible rearrangement of EGF receptor gene in primary human brain tumours of glial origin. Nature 313: 144-147.

Liu P, Cleveland TE 4th, Bouyain S, Byrne PO, Longo PA, Leahy DJ. 2012. A single ligand is sufficient to activate EGFR dimers. Proc Natl Acad Sci 109: 10861-10866.

Livneh E, Prywes R, Kashles O, Reiss N, Sasson I, Mory Y, Ullrich A, Schlessinger J. 1986. Reconstitution of human epidermal growth factor receptors and its deletion mutants in cultured hamster cells. J Biol Chem 261: 1249012497.

Lu C, Mi LZ, Grey MJ, Zhu J, Graef E, Yokoyama S, Springer TA. 2010. Structural evidence for loose linkage between ligand binding and kinase activation in the epidermal growth factor receptor. Mol Cell Biol 30: 5432-5443.

Lynch TJ, Bell DW, Sordella R, Gurubhagavatula S, Okimoto RA, Brannigan BW, Harris PL, Haserlat SM, Supko JG, Haluska FG, et al. 2004. Activating mutations in the epidermal growth factor receptor underlying responsiveness of non-small-cell lung cancer to gefitinib. N Engl J Med 350: 2129-2139.

Macdonald JL, Pike LJ. 2008. Heterogeneity in EGF-binding affinities arises from negative cooperativity in an aggregating system. Proc Natl Acad Sci 105: 112-117.

Macdonald-Obermann JL, Pike LJ. 2009. The intracellular juxtamembrane domain of the epidermal growth factor (EGF) receptor is responsible for the allosteric regulation of EGF binding. J Biol Chem 284: 13570-13576.

Macdonald-Obermann JL, Piwnica-Worms D, Pike LJ. 2012. Mechanics of EGF receptor/ErbB2 kinase activation revealed by luciferase fragment complementation imaging. Proc Natl Acad Sci 109: 137-142.

Matsushita C, Tamagaki H, Miyazawa Y, Aimoto S, Smith SO, Sato T. 2013. Transmembrane helix orientation influences membrane binding of the intracellular juxtamembrane domain in Neu receptor peptides. Proc Natl Acad Sci 110: 1646-1651.

McLaughlin S, Smith SO, Hayman MJ, Murray D. 2005. An electrostatic engine model for autoinhibition and activation of the epidermal growth factor receptor (EGFR/ ErbB) family. J Gen Physiol 126: 41-53.

Mendrola JM, Berger MB, King MC, Lemmon MA. 2002. The single transmembrane domains of ErbB receptors self-associate in cell membranes. J Biol Chem 277: 4704-4712.

Mi LZ, Lu C, Li Z, Nishida N, Walz T, Springer TA. 2011. Simultaneous visualization of the extracellular and cytoplasmic domains of the epidermal growth factor receptor. Nat Struct Mol Biol 18: 984-989.

Moasser MM. 2007. Targeting the function of the HER2 oncogene in human cancer therapeutics. Oncogene 26: 6577-6592. 
Mok TS. 2011. Personalized medicine in lung cancer: What we need to know. Nat Rev Clin Oncol 8: 661-668.

Morrison P, Takishima K, Rosner MR. 1993. Role of threonine residues in regulation of the epidermal growth factor receptor by protein kinase $\mathrm{C}$ and mitogen-activated protein kinase. J Biol Chem 268: 15536-15543.

Ogiso H, Ishitani R, Nureki O, Fukai S, Yamanaka M, Kim JH, Saito K, Sakamoto A, Inoue M, Shirouzu M, et al. 2002. Crystal structure of the complex of human epidermal growth factor and receptor extracellular domains. Cell 110: 775-787.

Ohashi K, Maruvka YE, Michor F, Pao W. 2013. Epidermal growth factor receptor tyrosine kinase inhibitor-resistant disease. J Clin Oncol 31: 1070-1080.

Paez JG, Jänne PA, Lee JC, Tracy S, Greulich H, Gabriel S, Herman P, Kaye FJ, Lindeman N, Boggon TJ, et al. 2004 EGFR mutations in lung cancer: Correlation with clinical response to gefitinib therapy. Science 304: 1497-1500.

Pao W, Miller V, Zakowski M, Doherty J, Politi K, Sarkaria I, Singh B, Heelan R, Rusch V, Fulton L, et al. 2004. EGF receptor gene mutations are common in lung cancers from "never smokers" and are associated with sensitivity of tumors to gefitinib and erlotinib. Proc Natl Acad Sci 101: 13306-13311.

Pentassuglia L, Sawyer DB. 2009. The role of Neuregulin1及/ErbB signaling in the heart. Exp Cell Res 315: 627637.

Qiu C, Tarrant MK, Choi SH, Sathyamurthy A, Bose R, Banjade S, Pal A, Bornmann WG, Lemmon MA, Cole PA, et al. 2008. Mechanism of activation and inhibition of the HER4/ErbB4 kinase. Structure 16: 460-467.

Red Brewer M, Choi SH, Alvarado D, Moravcevic K, Pozzi A, Lemmon MA, Carpenter G. 2009. The juxtamembrane region of the EGF receptor functions as an activation domain. Mol Cell 34: 641-651.

Rico B, Marín O. 2011. Neuregulin signaling, cortical circuitry development and schizophrenia. Curr Opin Genet Dev 21: 262-270.

Riese DJ II, Stern DF. 1998. Specificity within the EGF family/ErbB receptor family signaling network. Bioessays 20: $41-48$

Russ WP, Engelman DM. 2000. The GxxxG motif: A framework for transmembrane helix-helix association. $\mathrm{J} \mathrm{Mol}$ Biol 296: 911-919.

Scheck RA, Lowder MA, Appelbaum JS, Schepartz A. 2012. Bipartite tetracysteine display reveals allosteric control of ligand-specific EGFR activation. ACS Chem 7: 13671376

Schlessinger J. 1988. Signal transduction by allosteric receptor oligomerization. Trends Biochem Sci 13: 443-447.

* Schlessinger J. 2014. Receptor tyrosine kinases: Legacy of the first two decades. Cold Spring Harb Perspect Biol doi: $10.1101 /$ cshperspect.a008912.

Schneider MR, Wolf E. 2009. The epidermal growth factor receptor ligands at a glance. J Cell Physiol 218: 460-466.

Sharma SV, Bell DW, Settleman J, Haber DA. 2007. Epidermal growth factor receptor mutations in lung cancer. Nat Rev Cancer 7: 169-181.

Shi F, Telesco SE, Liu Y, Radhakrishnan R, Lemmon MA. 2010. ErbB3/HER3 intracellular domain is competent to bind ATP and catalyze autophosphorylation. Proc Natl Acad Sci 107: 7692-7697.

Sibilia M, Kroismayr R, Lichtenberger BM, Natarajan A, Hecking M, Holcmann M. 2007. The epidermal growth factor receptor: From development to tumorigenesis. Differentiation 75: 770-787.

* Song S, Rosen KM, Corfas G. 2013. Biological function of nuclear receptor tyrosine kinase action. Cold Spring Harb Perspect Biol 5: a009001.

Sorokin A. 1995. Activation of the EGF receptor by insertional mutations in its juxtamembrane regions. Oncogene 11: $1531-1540$.

Stamos J, Sliwkowski MX, Eigenbrot C. 2002. Structure of the epidermal growth factor receptor kinase domain alone and in complex with a 4-anilinoquinazoline inhibitor. J Biol Chem 277: 46265-46272.

Thiel KW, Carpenter G. 2007. Epidermal growth factor receptor juxtamembrane region regulates allosteric tyrosine kinase activation. Proc Natl Acad Sci 104: 19238 19243.

Tong J, Taylor P, Peterman SM, Prakash A, Moran MF. 2009. Epidermal growth factor receptor phosphorylation sites Ser991 and Tyr998 are implicated in the regulation of receptor endocytosis and phosphorylations at Ser1039 and Thr1041. Mol Cell Proteomics 8: 2131-2144.

Ullrich A, Schlessinger J. 1990. Signal transduction by receptors with tyrosine kinase activity. Cell 61: 203-212.

* Valley CC, Lidke KA, Lidke DS. 2014. The spatiotemporal organization of erbB receptors: Insights from microscopy. Cold Spring Harb Perspect Biol doi: 10.1101/ cshperspect.a020735.

Vivanco I, Robins HI, Rohle D, Campos C, Grommes C, Nghiemphu PL, Kubek S, Oldrini B, Chheda MG, Yannuzzi N, et al. 2012. Differential sensitivity of gliomaversus lung cancer-specific EGFR mutations to EGFR kinase inhibitors. Cancer Discov 2: 458-471.

* Wagner MJ, Stacey MM, Liu BA, Pawson T. 2013. Molecular mechanisms of SH2- and PTB-domain-containing proteins in receptor tyrosine kinase signaling. Cold Spring Harb Perspect Biol doi: 10.1101/cshperspect. a008987.

Walton GM, Chen WS, Rosenfeld MG, Gill GN. 1990. Analysis of deletions of the carboxyl terminus of the epidermal growth factor receptor reveals self-phosphorylation at tyrosine 992 and enhanced in vivo tyrosine phosphorylation of cell substrates. J Biol Chem 265: 1750-1754.

Ward CW, Hoyne PA, Flegg RH. 1995. Insulin and epidermal growth factor receptors contain the cysteine repeat motif found in the tumor necrosis factor receptor. Proteins 22: 141-153.

Welsh JB, Gill GN, Rosenfeld MG, Wells A. 1991. A negative feedback loop attenuates EGF-induced morphological changes. J Cell Biol 114: 533-543.

Wilson KJ, Gilmore JL, Foley J, Lemmon MA, Riese DJ II. 2009. Functional selectivity of EGF family peptide growth factors: Implications for cancer. Pharmacol Ther 122: $1-8$.

Wofsy C, Goldstein B, Lund K, Wiley HS. 1992. Implications of epidermal growth factor (EGF) induced egf receptor aggregation. Biophys J 63: 98-110. 


\section{M.A. Lemmon et al.}

Wood ER, Truesdale AT, McDonald OB, Yuan D, Hassell A, Dickerson SH, Ellis B, Pennisi C, Horne E, Lackey K, et al. 2004. A unique structure for epidermal growth factor receptor bound to GW572016 (Lapatinib): Relationships among protein conformation, inhibitor offrate, and receptor activity in tumor cells. Cancer Res 64: 6652-6659.

Wood ER, Shewchuk LM, Ellis B, Brignola P, Brashear RL, Caferro TR, Dickerson SH, Dickson HD, Donaldson KH, Gaul M, et al. 2008. 6-Ethynylthieno[3,2-d]- and 6-ethynylthieno[2,3-d]pyrimidin-4-anilines as tunable covalent modifiers of ErbB kinases. Proc Natl Acad Sci 105 2773-2778.
Yarden Y, Schlessinger J. 1987. Epidermal growth factor induces rapid, reversible aggregation of the purified epidermal growth factor receptor. Biochemistry 26: 1443-1451.

Yarden Y, Sliwkowski MX. 2001. Untangling the ErbB signalling network. Nat Rev Mol Cell Biol 2: 127-137.

Zhang X, Gureasko J, Shen K, Cole PA, Kuriyan J. 2006. An allosteric mechanism for activation of the kinase domain of epidermal growth factor receptor. Cell 125: 11371149.

Zhang H, Berezov A, Wang Q, Zhang G, Drebin J, Murali R, Greene MI. 2007. ErbB receptors: From oncogenes to targeted cancer therapies. J Clin Invest 117: 2051-2058. 


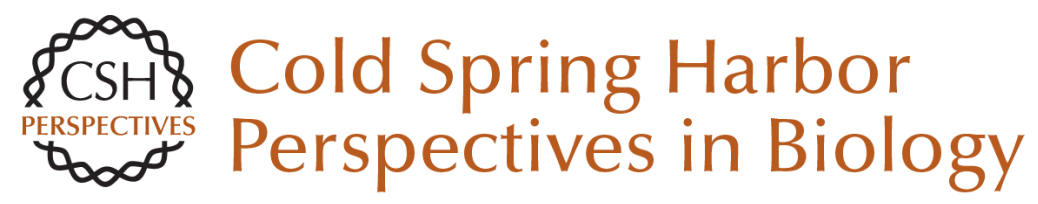

\section{The EGFR Family: Not So Prototypical Receptor Tyrosine Kinases}

Mark A. Lemmon, Joseph Schlessinger and Kathryn M. Ferguson

Cold Spring Harb Perspect Biol 2014; doi: 10.1101/cshperspect.a020768

Subject Collection Signaling by Receptor Tyrosine Kinases

CSF-1 Receptor Signaling in Myeloid Cells

E. Richard Stanley and Violeta Chitu

The EGFR Family: Not So Prototypical Receptor Tyrosine Kinases

Mark A. Lemmon, Joseph Schlessinger and Kathryn M. Ferguson

Tie2 and Eph Receptor Tyrosine Kinase Activation and Signaling

William A. Barton, Annamarie C. Dalton, Tom C.M. Seegar, et al.

The Spatiotemporal Organization of ErbB

Receptors: Insights from Microscopy

Christopher C. Valley, Keith A. Lidke and Diane S. Lidke

Insulin Receptor Signaling in Normal and Insulin-Resistant States

Jérémie Boucher, André Kleinridders and C. Ronald Kahn

Central Role of RET in Thyroid Cancer Massimo Santoro and Francesca Carlomagno

Receptor Tyrosine Kinase-Mediated Angiogenesis Michael Jeltsch, Veli-Matti Leppänen, Pipsa Saharinen, et al.

Biology of the TAM Receptors Greg Lemke
The Genesis of Tyrosine Phosphorylation Tony Hunter

Structure-Function Relationships of ErbB RTKs in the Plasma Membrane of Living Cells

Donna J. Arndt-Jovin, Michelle G. Botelho and Thomas M. Jovin

Receptor Tyrosine Kinases: Legacy of the First

Two Decades Joseph Schlessinger

The Role of Ryk and Ror Receptor Tyrosine Kinases in Wnt Signal Transduction Jennifer Green, Roel Nusse and Renée van Amerongen

Regulation of Receptor Tyrosine Kinase Ligand Processing Colin Adrain and Matthew Freeman

Molecular Mechanisms of SH2- and PTB-Domain-Containing Proteins in Receptor Tyrosine Kinase Signaling Melany J. Wagner, Melissa M. Stacey, Bernard A. Liu, et al.

Eph Receptor Signaling and Ephrins Erika M. Lisabeth, Giulia Falivelli and Elena B. Pasquale

Effects of Membrane Trafficking on Signaling by

Receptor Tyrosine Kinases Marta Miaczynska

For additional articles in this collection, see http://cshperspectives.cshlp.org/cgi/collection/

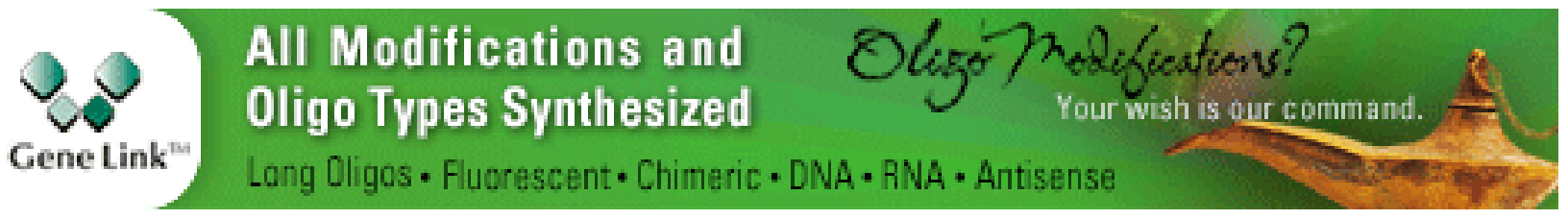


For additional articles in this collection, see http://cshperspectives.cshlp.org/cgi/collection/

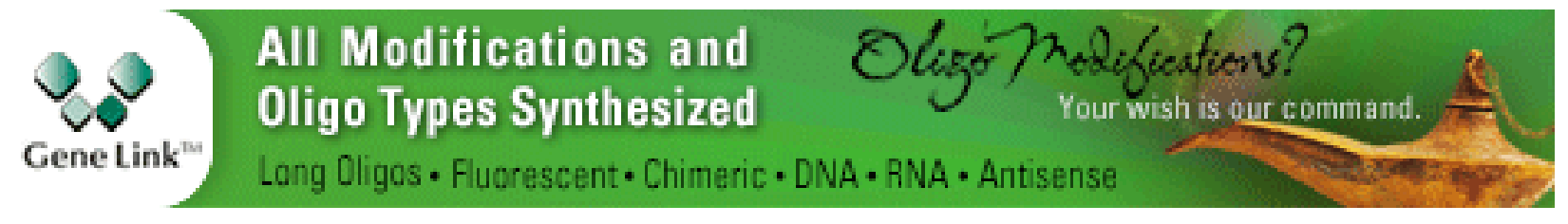

Copyright @ 2014 Cold Spring Harbor Laboratory Press; all rights reserved 